\title{
NOTAS SOBRE EL 'CACAHUETE' Y LA 'AVELLANA' EN ANDALUCIA
}

\author{
Ana Isabel Navarro Carrasco \\ (Universidad de Alicante)
}

\begin{abstract}
El Diccionario de la Academia' en la primera acepción de la voz avellana dice:

'Fruto del avellano; es casi esférico, de uno o dos centímetros de diámetro, con corteza dura, delgada y de color canela, dentro de la cual, y cubierta con una película rojiza, hay una carne blanca, aceitosa y de gusto agradable ${ }^{2}$.
\end{abstract}

La segunda y tercera acepción no nos sirven para nuestros propósitos ${ }^{3}$. Evidentemente, la Academia se está refiriendo a la Corylus Avellana. Lo que sucede es que nuestra Institución, con todos sus muchos méritos, no ha tenido en cuenta que en Andalucía la voz avellana no se identifica con la Corylus Avellana sino que designa al 'cacahuete', es decir, a la Arachis hypogea.

En Andalucía el término avellana es el fruto de la

'Planta papilonácea anual procedente de América, con tallo rastrero y velloso, hojas alternas lobuladas y flores amarillas. El fruto tiene cáscara coriácea y, según la variedad, dos a cuatro semillas blancas y oleaginosas, comestibles después de tostadas. Se cultiva también para la obtención del aceite $^{14}$.

Real Academia Española, Diccionario de la lengua española, Madrid, Espasa-Calpe, 1992, $21^{:}$edición. En adelante DRAE.

2 S. v. avellana.

3 'Carbón mineral de la cuenca de Puertollano, lavado y clasificado, cuyos trozos han de tener un tamaño reglamentario comprendido entre 15 y 25 milímetros', 'de la India, o índico, mirobálano', segunda y tercera acepción, respectivamente.

¿ DRAE, s. v., cacahuete. 
Esta definición que da la Academia para el cacahuete es el sentido que posee la voz avellana en Andalucía.

En estas páginas que siguen tenemos la intención de poner de relieve, utilizando los datos del Atlas Lingüístico y Etnográfico de Andalucía ${ }^{5}$, el ALEA, que la voz cacahuete es sustituida en la mayor parte de Andalucía por el término avellana. Si al 'cacahuete' se le llama avellana, ¿cómo se le llamará a la 'aveIlana (Corylus Avellana)'? Estamos ante dos frutos distintos y la lengua utiliza mecanismos terapéuticos para evitar la homonimia. Entonces resulta que 'avellana (Corylus Avellana)' recibe otras denominaciones distintas a las de la lengua oficial. Normalmente se utiliza un complemento determinativo avellana de... para señalar el tipo de avellana al que se está refiriendo el hablante, puesto que en Andalucía hay clara conciencia lingüística de que la avellana es el 'cacahuete'.

El mapa II, 350 del ALEA nos muestra la onomasiología de 'cacahuete (Arachis hypogea)'. Si analizamos dicha carta linguística nos encontramos con dos bloques fundamentales de respuestas:

1) cacahuete y variantes: al/rcahuete, arcahuei, carcahuei, cacahué, principalmente.

2) avellana (y vars. fonéts.: allrvellana).

1) Cacahuete y variantes se ciñe a las provincias de Almería, Granada, Jaén, una localidad de Málaga, otra de Cádiz y otra de Sevilla.

La voz cacahuete, en el mapa, aparece en localidades aisladas: dos del este y una del sudeste de Almería ${ }^{6}$.

Alcahuete o arcahuete está muy extendido por toda la provincia de Almería, localidades del este de Granada en contacto con la mencionada provincia y puntos del cuadrante nordeste de Jaén ${ }^{7}$.

Arcahuei se sitúa en el cuadrante sudeste de Granada ${ }^{8}$.

Carcahuei se ciñe a la provincia de Granada y una localidad de Almería" y cacahuei a puntos de Granada y Almería, más uno de Jaén ${ }^{10}$.

M. Alvar con la colaboración de A. Llorente y G. Salvador, Granada, Universidad-CSIC, $1961-1973,6$ tomos.

Al $405,509,600$.

Al 100, 300, 301, 302, 303, 400, 401, 500, 501, 502, 504, 506, 507, 508, 601, 602; Gr 506, 600,$602 ; \mathrm{J} 100,200,201,202$.

Al 508

Gr $505,510,511,512,513,514,515,603,604$.

Gr $301,302,304,305,306,308,401,403,407,408,409,410,500,502,503,508,509,510$;

10. Gr $300,307,402,404,405,504,507 ;$ Al $201,203,403 ;$ J 307 . 
Finalmente, la forma cacahué en puntos aislados de Granada, Jaén, Almería, Cádiz, Sevilla y Málaga" y cacahuei, igualmente de manera aislada, en Almería, Granada y Jaén ${ }^{12}$.

Cacahuete y todas sus variantes caracterizan a las provincias orientales de Almería, Granada y Jaén —-sobre todo a las dos primeras-, mientras que en el resto de la región no aparece la voz y, cuando lo hace, carece de valor significativo. En Ma 408 se halla en segundo lugar, lo cual resulta explicable por dos motivos:

1) El término no tiene arraigo en la localidad.

2) El término pertenece a la lengua general y el informante lo ha podido oír y conservar en su memoria.

O, por ejemplo, en Ca 300, la misma capital de la provincia, cacahué sería la forma de prestigio del centro urbano frente al resto de las localidades de la provincia donde de manera general figura avellana o las variantes alvellana, arvellana.

Cacahuete, según los datos que tomamos de Corominas ${ }^{13}$, procede del náhuatl TLALKAKAWALTL 'íd.', compuesto de tallil 'tierra' y KAKAWALTL 'cacao', propiamente 'cacao de tierra'. En la denominación científica Arachis hypogaea se destaca la característica "bajo tierra", como señala León Portilla ${ }^{14}$, el cual afirma que existe una variante muy extendida en Méjico y otros países de América Central, donde en lugar de cacahuete, se dice cacahuate. Corominas explica dicha alteración por un falso análisis de cacahuete como diminutivo de cacao y además por influjo de la palabra alcahuete ${ }^{15}$.

2) Avellana (y vars. fonéts.: arvellana, alvellana) 'cacahuete' aparece de manera total en las provincias de Huelva, Sevilla ${ }^{16}, \mathrm{Cádiz}^{17}$, Málaga, Córdoba, la mayor parte de las localidades de Jaén, algunas del nordeste de Granada — principalmente- y varias de Almería ${ }^{18}$.

Arvellana, alvellana 'cacahuete' podríamos decir que es general a toda la región, pero por estar ocupadas las provincias orientales de Almería, Granada y

11 Gr 406, 501, 601; Al 505; J 103, 308; Ca 300; Se 600; Ma 408.

$12 \mathrm{Al} 201,203,403 ;$ Gr 300, 307, 402, 404, 405, 504, 507; J 307.

1.7 J. Corominas; J. A. Pascual, Diccionario Crítico Etimológico Castellano e Hispánico, Madrid, Gredos, 1980-1991, 6 tomos, s. v. cacahuete.

14 M. León Portilla, "Nahuatlismos en el castellano de España", LEA, IV (1982), págs. $213-$ 238: págs. 230-231.

15 Op.cit., s. v. cacahuete.

If Excepto Se 600.

17 Salvo Ca 300.

1* Sólo indicamos las localidades de Jaén, Granada y Almería en las que figura la voz, ya que en el resto de las provincias mencionadas su aparición es total: $J 101,102,203,204,205,300,301$, $302,303,305,306,307,308,309,400.401,402,403,404,500,501,502,503,504,600$; Gr 200 . 201, 202, 203, 303, 400; Al 200, 201, 202, 203, 303, 400; Al 200, 202, 203, 204, 205, 402, 404, 501 , 503. 
- Jaén también por la voz cacahuete (y variantes), el término al/rvellana se concentra en las provincias occidentales (Huelva, Sevilla, Cádiz, Málaga) y en Córdoba.

Como hemos dicho, el DRAE no registra avellana como 'cacahuete'; tampoco figura en el Vocabulario Andaluz de Alcalá Venceslada' ${ }^{19}$. La voz por lo demás con este significado se registra en Mérida $^{20}$ y en Murcia ${ }^{21}$ con lo cual vemos que el radio de acción de dicha denominación es más amplio que el restringido a Andalucía.

Los motivos que llevan a identificar la voz avellana con 'cacahuete' habría que buscarlos en las características mismas del fruto, así como en las dificultades de los hablantes ante una palabra exranjera: cacahuete. En efecto, tanto el 'cacahuete' como la 'avellana' son frutos secos comestibles de tipo parecido. El vocablo cacahuete se introduciría en España junto con el fruto tras el descubrimiento de América. Los hablantes no estaban acostumbrados a este tipo de voces extranjeras y le dieron al fruto un nombre (avellana) que ya poseían para otro, si no similar, sí con características afines.

El hablante es perfectamente consciente de que da el mismo nombre a dos cosas distintas: avellana 'fruto del avellano', avellana 'cacahuete'. De ahí que al 'fruto del avellano' se le denomine al/rvellana americana ${ }^{22}$, al/rvellana de los toros, al/rvellana re(d)onda, al/rvellana de horchata, allrvellana catalana, al/rvellana serrana, al/rvellana fina, al/rvellana de cáscara dura, al/rvellana pilonga, etc. El mapa del ALEA, II, 349 nos muestra todas esas denominaciones, además de avellana (y vars. fonéts.: al/rvellana) como 'fruto del avellano'.

1) Avellana (y vars. fonéts.: allrvellana) 'fruto del avellano (Corylus avella$n a)^{\prime}$ - sin más adjetivos que sirvan para denominar al fruto- se emplea justamente en aquella zona en la que el 'cacahuete' se llama cacahuete (y variantes). Así pues, avellana (y vars. fonéts.: al/rvellana) es general en Almería, Granada y sudeste de Sevilla. Figura también en puntos esporádicos de Jaén, Córdoba, Málaga y Cádiz ${ }^{23}$.

19 Madrid, Gredos, 1980, reimpresión de la segunda edición, Madrid, RAE, 1951.

20 A. Zamora Vicente, El habla de Mérida y sus cercanías, Madrid, Anejo XXIX de la RFE, CSIC, 1943.

21 J. García Soriano, Vocabulario del dialecto murciano, Murcia, Editora Regional, 1980, edición facsímil de la primera, Madrid, 1932.

22 Acerca de la alternancia de -l/-r implosivas en español vid. el importante estudio de A. Alonso y R. Lida, "Geografía fonética de L y R implosivas en español", RFH, VII (1945), págs. 313 345, ahora en A. Alonso, Estudios lingüisticos. Temas hispanoamericanos, Madrid, Gredos, 1976 , 3" ed., reimpresión, págs. 266-331. La alternancia a-/al- es muy frecuente en nuestra lengua, favorecida por los arabismos de forma dúplice. Cfr. M. Alvar, El español hablado en Tenerife, Madrid, Anejo LXIX de la RFE, CSIC, 1959, pág. 44.

23 Al 100, 201, 301, 401, 402, 403, 405, 500, 501, 502, 503, 504, 505, 506, 507, 508, 509, 600, 601,602 ; Gr 202, 300, 301, 302, 304 (avellanilla), 305, 306, 307, 308, 401, 402, 403, 404, 405, 406, $408,409,410,501,502,503,504,505,506,508,509,510,511,512,514,515,600,601,602,603$, 604; J 100, 201, 202, 302, 304, 308, 400, 502; Co 400; Ma 403, 407; Ca 201, 602; Se 403, 404, 600. 
2) Al/rvellana americana 'fruto del avellano' es general en Huelva, Sevilla, este de Cádiz, Málaga, puntos de Córdoba, Jaén, oeste de Granada y alguno del norte y este de Almería ${ }^{24}$.

El adjetivo americana suele presentar aféresis ((a)mericana), además, en ocasiones, aparece la forma almericana.

A veces, americana funciona como sustantivo y denomina directamente al concepto. De esta manera tenemos,

'fruto del avellano' 'cacahuete'
americana

El fruto del avellano no fue introducido en la Península a raíz de la conquista de América sino que era conocido en Europa desde tiempos antiguos. Lo que sí se introdujo tras el descubrimiento del Nuevo Mundo fue el 'cacahuete' — como hemos dicho anteriormente-. Unas veces los hablantes lo llamaron por su nombre primitivo - con todas cuantas deformaciones fonéticas posibles por el carácter extraño de la palabra-y otras lo llamaron avellana identificándolo con un fruto de características similares. Pero el arraigo que adquirió el cultivo del cacahuete hizo que el fruto más conocido pasase a denominarse avellana 'cacahuete', mientras que avellana americana y otros similares se reservara para el fruto del árbol, menos común que el anterior, y pensando - sobre todo-en que precisamente éste último era el importado de América.

Avellana americana 'fruto del avellano' también se halla en el sudeste de Murcia 25 .

3) Avellana cordobesa es otra forma de evitar la homonimia entre dos frutos diferentes que han confluido en la misma denominación. De esta manera tenemos,

'fruto del avellano' $\quad$ 'cacahuete'
avellana cordobesa

Al/rvellana cordobesa es la denominación general en la mitad sur de Córdoba y en gran parte de Jaén ${ }^{26}$. El adjetivo cordobesa nos está indicado que se trata de un cultivo de Córdoba.

${ }^{24}$ Indicamos cuando se trata de americana 'fruto del avellano', por exclusión avellana americana 'íd.' en los restantes casos: H 100 ((a)mericana), 101 (almericana), 102, 200, 201, 202, 203, 204, 300, 301, 302, 400, 401, 402, 500, 501, 504, 600, 601, 602, 603; Se 100, 101, 102, 200, 201, $300,301,302,304,305,306,307,310,400$ ((a)mericana), 401, 405, 500, 501, 502, 503, 602, 603; $\mathrm{Ca} 200,202,204,205,400,600 ; \mathrm{Ma} 100,102,200,201,202,203,300$ ((a)mericana), 301, 302, 303 ((a)mericana), 304, 400, 401, 402, 404, 405, 406, 408, 500, 501, 502, 503, 600 ((a)mericana); Co 101 (armericana), 102, 104, 202 (armericana), 300, 601, 605, 608, 609; J 204, 303, 305, 307, 309, 402, 403, 404, 500, 503, 504; Gr 303, 500, 507; Al.200, 204, 404.

2.5 J. García Soriano, Vocabulario del dialecto murciano, op cit.

26. Co 103, 30l, 302, 401, 402, 403, 600, 601, 603, 604, 606; J 101, 102, 103, 203, 300, 301, $306,308,401$. 
4) Al/rvellana de los toros en la mitad occidental de la provincia de Cádiz ${ }^{27}$. La denominación delata el uso que se hace del fruto: alimento de las reses bravas en una zona donde se crían toros de raza.

5) Allrvellana re(d)onda en localidades del centro y sur de Sevilla y una del sur de Huelva ${ }^{28}$.

El 'fruto del avellano', como bien se sabe, presenta la forma de una bolita redonda mientras que el 'cacahuete' es de forma alargada. De esta manera, se establece la distinción entre

$\begin{array}{cl}\text { 'fruto del avellano' } & \text { 'cacahuete' } \\ \text { allrvellana re(d)onda } & \text { avellana }\end{array}$

En H 502 se establece la siguiente oposición:

'fruto del avellano' 'cacahuete'
allrvellana re(d)onda allrvellana larga

6) Al/rvellana de horchata en un par de localidades del nordeste de Grana$\mathrm{da}^{29}$.

El complemento determinativo de horchata nos indica la utilización que se hace de ella. Aunque específicamente la horchata se haga de chufas, puede hacerse también con el 'fruto del avellano':

$\begin{array}{cl}\text { 'fruto del avellano' } & \text { 'cacahuete' } \\ \text { avellana de horchata } & \text { avellana }\end{array}$

7) Al/ruellana catalana en un par de localidades de Cádiz ${ }^{30}$.

8) Otras denominaciones son: al/rvellana pelicana ${ }^{31}$, al/rvellana espericana ${ }^{32}$, avellana serrana ${ }^{33}$ que también se recoge en Mérida ${ }^{34}$ y el adjetivo serrana alude al hecho de que el avellano se cultive en sierras. Avellana fina en un par de

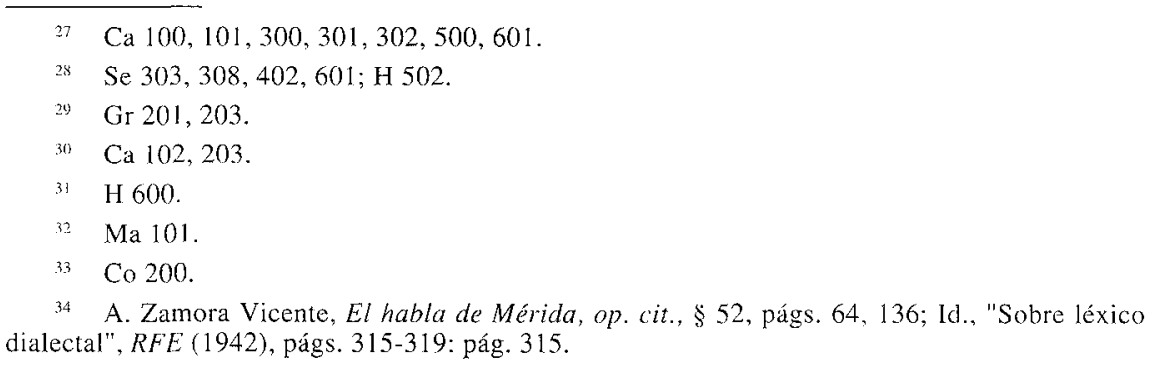


localidades del nordeste de la provincia de Granada ${ }^{35}$ y también en el nordeste de la región murciana $a^{36}$. Avellana de cáscara dura ${ }^{37}$ tiene fácil explicación pues alude a la dureza de la cáscara del 'fruto del avellano', frente a la fragilidad de la del 'cacahuete'. Finalmente, avellana pilonga ${ }^{38}$ imitando a castaña pilonga.

\section{CONSIDERACIONES FINALES}

En estas páginas hemos puesto de relieve cómo actúa la terapéutica verbal en la lengua para evitar la homonimia. Si en Andalucía - sobre todo- al 'cacahuete' se le llama avellana, la 'avellana' recibe otras denominaciones para no dar el mismo nombre a dos frutos diferentes.

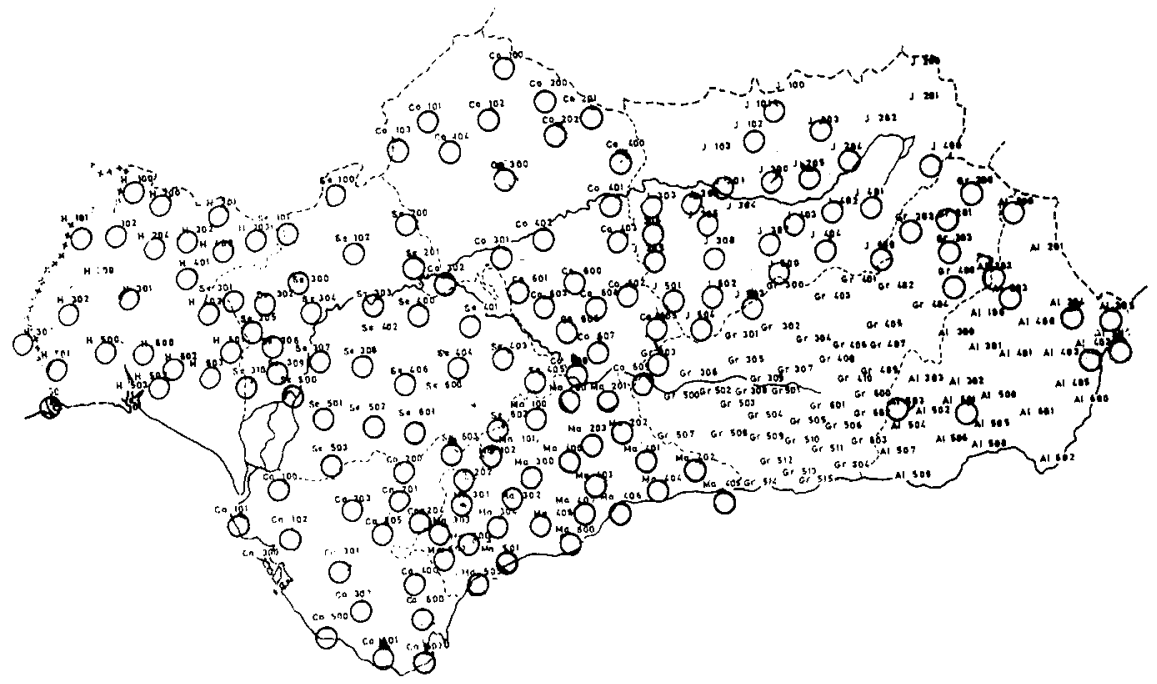

o avellana

'cacahuete'

$35 \operatorname{Gr} 200,400$.

3 J. García Soriano, Vocabulario del dialecto murciano, op cit.

$.7 \mathrm{~J} 600$.

$3 R \quad$ J 501 